\title{
Boron Segregation and Electrical Properties in Polycrystalline SiGeC
}

\author{
E. J. Stewart, M. S. Carroll*, and J.C. Sturm \\ Center for Photonics and Optoelectronic Materials, Department of Electrical Engineering \\ Princeton University, Princeton NJ \\ * present address: Agere, Murray Hill, NJ
}

\begin{abstract}
Previously, it has been reported that PMOS capacitors with heavily boron-doped polycrystalline $\mathrm{SiGeC}$ gates are less susceptible to boron penetration than those with poly $\mathrm{Si}$ gates [1]. Boron appears to accumulate in the poly SiGeC layers during anneals, reducing boron outdiffusion from the gate despite high boron levels in the poly $\mathrm{SiGeC}$ at the gate/oxide interface. In this abstract, we report clear evidence of strong boron segregation to polycrystalline $\mathrm{SiGeC}$ layers from poly $\mathrm{Si}$, with boron concentration in poly $\mathrm{SiGeC}(\mathrm{Ge}=25 \%, \mathrm{C}=1.5 \%)$ increasing to four times that of adjacent poly $\mathrm{Si}$ layers. A separate experiment confirms that this result is not due to any SIMS artifacts. Electrical measurements of heavily in-situ doped single layer samples show that the conductivity of poly $\mathrm{SiGeC}$ is similar to poly $\mathrm{Si}$ and remains roughly constant with annealing at $800^{\circ} \mathrm{C}$. However, in a two-layer sample where the poly SiGeC is initially lightly doped and subsequently heavily doped by diffusion by from an adjacent poly $\mathrm{Si}$ layer, conductivity appears lower than in poly $\mathrm{Si}$.
\end{abstract}

\section{INTRODUCTION}

Heavily boron-doped polysilicon is typically used as the gate material for modern p-channel MOSFETs. Doping the polysilicon gate is usually achieved by ionimplantation using $\mathrm{B}$ or $\mathrm{BF}_{2}{ }^{+}$, followed by an anneal to activate the dopant and drive it throughout the gate. For devices with very thin gate oxides, boron can actually diffuse through the gate oxide and into the substrate during this activation anneal. This boron penetration into the substrate changes the doping in the channel, causing undesirable positive threshold voltage shifts in the device [2].

Previously, it has been shown that, by placing a thin layer of polycrystalline $\mathrm{SiGeC}$ at the bottom of the polysilicon gate, boron penetration can be greatly suppressed for both PMOS capacitors and p-channel MOSFETs [1,3]. It is well known that boron diffusion in single-crystal $\mathrm{SiGeC}$ can be over an order of magnitude slower than in single-crystal $\mathrm{Si}$ [4]. However, the polycrystalline $\mathrm{SiGeC}$ gate layers do not appear to be acting as boron diffusion barriers (grain boundary diffusion may be enhancing diffusion in poly vs single crystal $\mathrm{SiGeC}$ ). Instead, boron diffuses through and appears to accumulate in the poly $\mathrm{SiGeC}$ layers during the anneal, giving a high dopant level at the gate/oxide interface [1,3]. This tendency for boron to segregate to poly SiGeC layers may be responsible for the reduced boron penetration.

In this work, we present clear independent evidence of strong boron segregation to polycrystalline $\mathrm{SiGeC}$ layers. We also examine the electrical properties of boron in polycrystalline $\mathrm{SiGeC}$ layers subjected to annealing. 


\section{EXPERIMENT}

Thermal oxides ( $200 \mathrm{~nm})$ were first grown on n-type substrates. Polycrystalline layers were then deposited by Rapid Thermal Chemical Vapor Deposition at $\sim 575^{\circ} \mathrm{C}$ for poly $\mathrm{SiGe}$ and poly $\mathrm{SiGeC}$ and $700^{\circ} \mathrm{C}$ for poly $\mathrm{Si}$. $\mathrm{SiH}_{4}, \mathrm{GeH}_{4}, \mathrm{SiCH}_{6}$, and $\mathrm{B}_{2} \mathrm{H}_{6}$ were used as source gases for silicon, germanium, carbon, and boron, respectively. For the $\mathrm{SiGe}$ or $\mathrm{SiGeC}$ layers, $\mathrm{Ge}$ concentrations were $\sim 25 \%$ and $\mathrm{C}$ concentrations were $\sim 1.5 \%$. Previous work shows that in single crystal $\mathrm{SiGeC}$ layers grown under similar conditions, most of the carbon is substitutional [5]. To study segregation, a two layer structure was grown, consisting of a $\sim 100 \mathrm{~nm}$ lightly (in-situ) doped polycrystalline $\mathrm{SiGeC}$ layer underneath a $300 \mathrm{~nm}$ heavily (in-situ) doped poly Si layer. This sample was annealed at $800^{\circ} \mathrm{C}$ for long times to allow boron to move from the heavily doped poly Si layer to the lightly doped poly SiGeC layer. SIMS profiles, sheet resistance, and spreading resistance measurements were taken before and after the anneal to examine boron diffusion and electrical activity in the sample.

To study the electrical properties of isolated poly $\mathrm{SiGeC}$ layers subjected to annealing, single layers of heavily in-situ doped ([B] $\left.\sim 1 \times 10^{20} \mathrm{~cm}^{-3}\right)$ poly $\mathrm{Si}(\sim 300 \mathrm{~nm})$, $\mathrm{SiGe}(\sim 100 \mathrm{~nm})$, and $\mathrm{SiGeC}(\sim 100 \mathrm{~nm})$ were grown and annealed under the same conditions as the two-layer sample. Along with SIMS and sheet resistance measurements, Hall measurements were also taken for these samples.

\section{BORON SEGREGATION TO POLYCRYSTALLINE SIGEC}

Boron segregation to poly $\mathrm{SiGeC}$ is clearly demonstrated in the two-layer structure. SIMS profiles of this sample are plotted in figure 1. Before the anneal (asgrown sample), the poly Si layer is heavily doped at $\sim 4 \times 10^{19} \mathrm{~cm}^{-3}$, while the poly $\mathrm{SiGeC}$ layer is lightly doped at $\sim 2 \times 10^{18} \mathrm{~cm}^{-3}$. If there were no segregation between the layers, this profile would be expected to flatten out during the anneal. However, after an $800^{\circ} \mathrm{C}$,

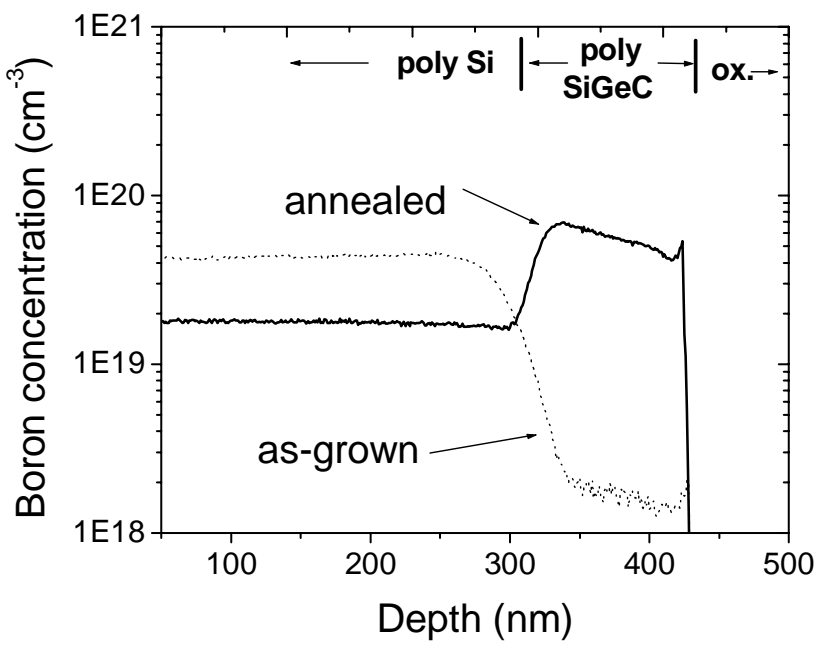

Figure 1: SIMS profiles of boron concentration in two-layer structure before and after annealing at $800^{\circ} \mathrm{C}$ for 44 hours in $\mathrm{N}_{2}$. 
44 hour anneal in $\mathrm{N}_{2}$, boron levels have risen in the poly SiGeC layer to $\sim 4-6 \times 10^{19} \mathrm{~cm}^{-3}$, while boron concentration has decreased in the poly Si to $\sim 1.5 \times 10^{19} \mathrm{~cm}^{-3}$, demonstrating strong segregation to the poly $\mathrm{SiGeC}$. Defining $\mathrm{m}$ as the ratio of boron concentration in the poly $\mathrm{SiGeC}$ to the poly $\mathrm{Si}$ at the interface, we find $\mathrm{m} \sim 4$ for these parameters $(\mathrm{Ge}=$ $25 \%, \mathrm{C}=1.5 \%$ ) and annealing conditions. A separate sample, consisting of several layers of poly $\mathrm{SiGeC}(\mathrm{Ge} \sim 20 \%$, C levels varied from $0 \%$ to $1 \%$ ) sandwiched between poly $\mathrm{Si}$ layers, revealed that boron segregation increases steadily with $\mathrm{C}$ concentration [3]. This sample, also annealed in $\mathrm{N}_{2}$ at $800^{\circ} \mathrm{C}$, gave a segregation coefficient $\mathrm{m} \sim 4.3$ for a $1 \%$ carbon level, roughly consistent with these results.

A separate experiment was carried out to confirm that the observed segregation is not attributable to a SIMS artifact associated with measuring boron in SiGeC layers with high $\mathrm{C}$ levels. Three samples were used for this experiment. The first was just a lightly doped $\left(\sim 1 \times 10^{15} \mathrm{~cm}^{-3}\right)$ n-type substrate. The second sample consisted of an n-type substrate, on top of which was grown a $\sim 80 \mathrm{~nm} \mathrm{SiGe} \mathrm{layer,} \mathrm{followed} \mathrm{by} \mathrm{a} \sim 50 \mathrm{~nm}$ Si cap (all undoped). The third sample was similar to the second, except a $\mathrm{SiGeC}$ layer was used in place of the SiGe. Ge and C levels were $20 \%$ and 1\%, respectively. All 3 samples were then ion-implanted with boron at several doses and energies to create a roughly flat boron profile in each sample from a depth of about $50 \mathrm{~nm}$ to $300 \mathrm{~nm}$. The implant conditions were identical for the 3 samples. No anneals were performed. SIMS measurements of boron were then taken for all 3 samples, expecting to see similar boron profiles in each (perhaps slightly different profiles are expected in the samples with $\mathrm{SiGe}$ and $\mathrm{SiGeC}$ layers vs. the all Si sample, due to a different stopping coefficient for boron in $\mathrm{SiGe}$ vs. Si). If SIMS measurements exaggerate boron levels in the $\mathrm{SiGeC}$ layers, then an anomalous spike in the measured SIMS profile might be expected in this sample. No such spike is observed, however. Figure 2 shows the SIMS plots of boron concentration vs. depth for the 3 samples. All samples have almost indistinguishable profiles, with boron levels rising quickly to $\sim 2 \times 10^{19} \mathrm{~cm}^{-3}$ at $50 \mathrm{~nm}$, leveling off, and then dropping at $\sim 300 \mathrm{~nm}$. In particular, no significant difference is seen between the samples with a SiGe

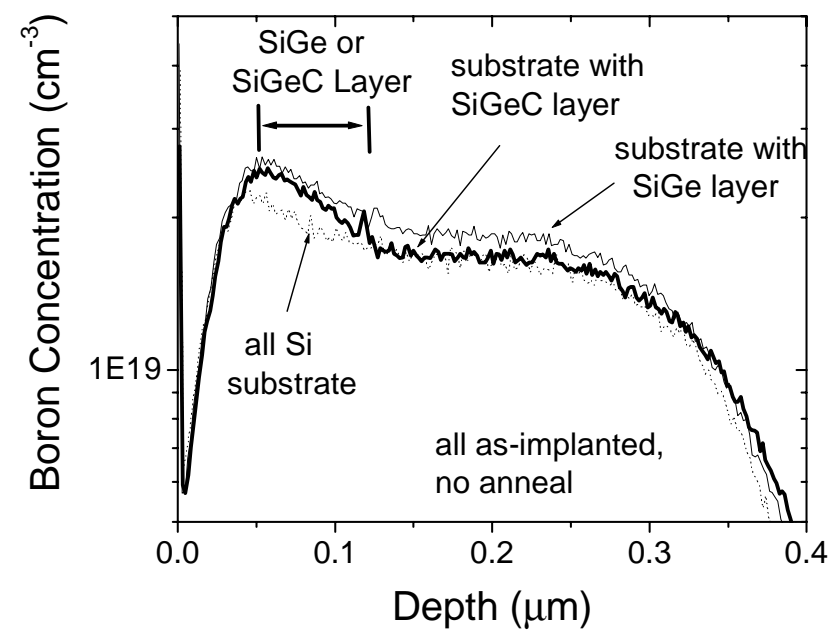

Figure 2: SIMS profiles of boron concentration for implanted samples. 
layer vs. a $\mathrm{SiGeC}$ layer, indicating that SIMS measurements are not exaggerating boron levels in SiGe layers with high C concentrations. This confirms that the segregation measured by SIMS on the two-layer poly sample is not a measurement artifact.

The mechanism driving the segregation is not known at this point. Weak boron segregation to strained single crystal SiGe layers vs. $\mathrm{Si}(\mathrm{m} \sim 1.3)$ has been previously reported [6]. This has been explained by smaller boron atoms relieving strain in the strained $\mathrm{SiGe}$, and by the smaller bandgap of $\mathrm{SiGe}$ vs. Si [7]. However, $\mathrm{SiGeC}$ has less strain than $\mathrm{SiGe}$, and a bandgap closer to that of $\mathrm{Si}$, both of which predict less segregation to $\mathrm{SiGeC}$ vs. SiGe. This is opposite of what is observed. One possibility is the formation of $\mathrm{B}-\mathrm{C}$ related defects, which is discussed in the next section.

\section{ELECTRICAL PROPERTIES}

Electrical measurements indicate that boron incorporated by in-situ doping in polycrystalline $\mathrm{SiGeC}$ remains electrically active when subjected to furnace anneals. Figure 3 shows plots of resistivity, Hall mobility, and Hall carrier concentration vs. furnace anneal time at $800^{\circ} \mathrm{C}$ for the single layer in-situ doped samples. The as-grown
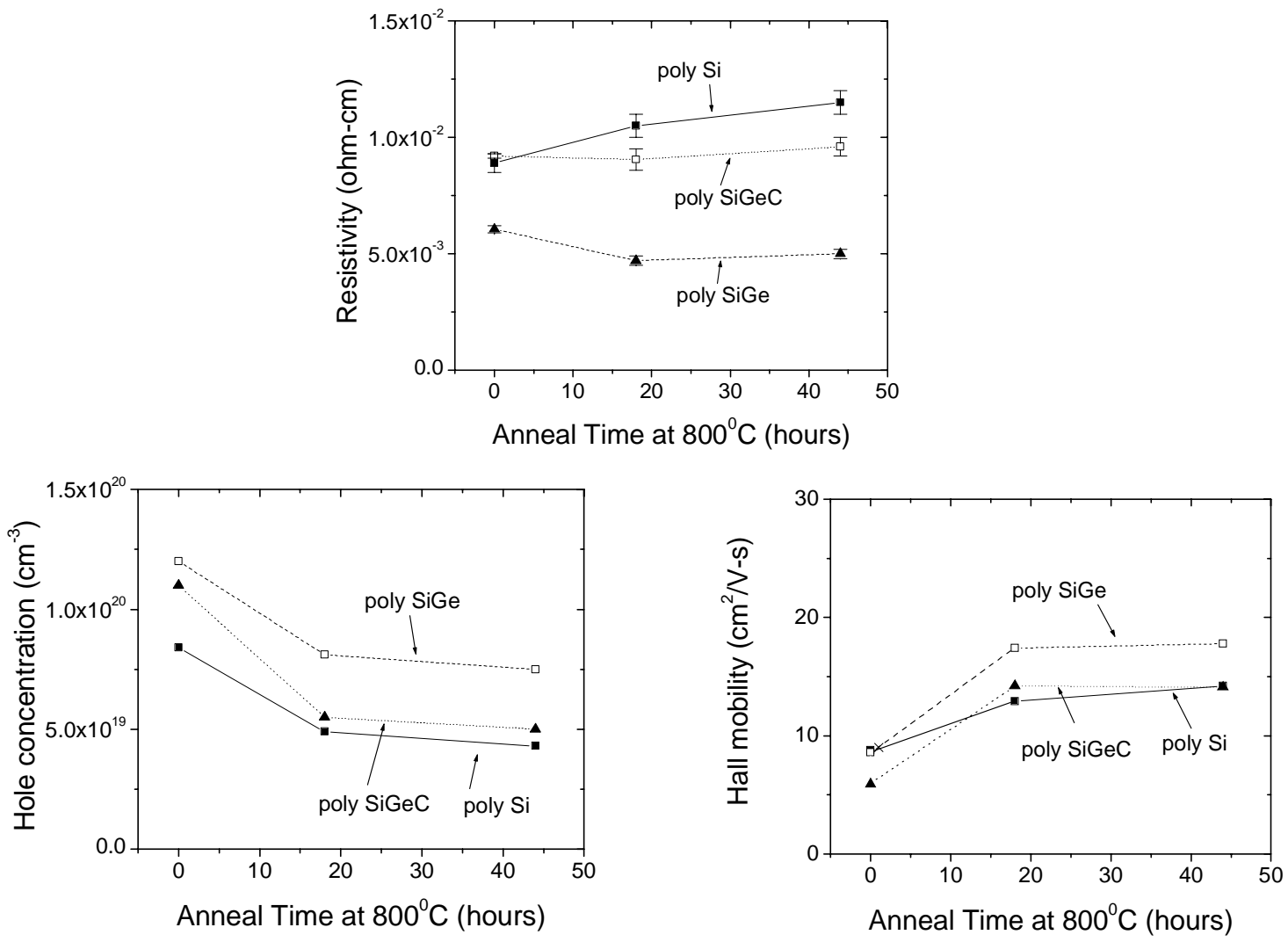

Figure 3: Resistivity, hall mobility, and hall concentration vs. anneal time at $800^{\circ} \mathrm{C}$ for single in-situ doped layers ([B] $10^{20}$ atoms $/ \mathrm{cm}^{3}$ ) of poly $\mathrm{Si}, \mathrm{SiGe}$, and $\mathrm{SiGeC}$. 
poly $\mathrm{SiGeC}$ sample has a resistivity equal to the poly $\mathrm{Si}$ sample, both being higher than the poly $\mathrm{SiGe}$ sample. As all samples are annealed, the resistivity of the poly $\mathrm{SiGeC}$ sample remains roughly constant and similar to the poly Si sample. This indicates that large amounts of boron are not becoming inactive due to the formation of some inactive carbon-related defect. This is not due to the lack of enough carbon atoms - even with $\sim 10^{20} \mathrm{~cm}^{-3}$ boron doping, there are still $\sim 7$ carbon atoms for every boron atom.

Hall measurements show that the carrier concentrations in all 3 samples decrease quickly and level off. This is qualitatively to be expected, since all samples are doped with boron above solid solubility limits at this temperature $\left(\sim 6 \times 10^{19} \mathrm{~cm}^{-3}\right.$ for poly Si [8]) and therefore should see a loss in substitutional boron with annealing. Hall mobilities increase with annealing however, offsetting the loss in conductivity caused by the reduced carrier concentration. Increased mobility in all samples may be due to an increase in grain size during the anneal.

Polycrystalline $\mathrm{SiGeC}$ appears less conductive than poly $\mathrm{Si}$, however, when boron diffuses and segregates into the layer rather than being incorporated in-situ during growth. Figure 4 shows sheet resistance and spreading resistance measurements of the two-layer sample used above to demonstrate segregation. Initially, as shown in figure 1, all of the dopant is in the poly $\mathrm{Si}$ layer, and thus the resistivity of the sample is dominated by the poly Si layer. As boron moves into the poly SiGeC layer during the anneal (also figure 1), the sheet resistance of the sample becomes more and more determined by the electrical properties of the poly $\mathrm{SiGeC}$ layer. As shown in figure 4, the sheet resistance of the sample goes up for longer anneal times, and, therefore, with more boron in the poly $\mathrm{SiGeC}$ layer. This suggests that the boron in the poly $\mathrm{SiGeC}$ is less conductive than in the poly Si. Spreading resistance plots of this sample confirm this result. After the anneal, even though the doping level in the poly $\mathrm{SiGeC}$ is at least 3 times as higher than in the poly $\mathrm{Si}$, the resistivity is only about equal, indicating $\sim 3 \mathrm{X}$ higher resistance for a given doping level. Whether this is due to a lower hole mobility or a lower level of boron activation in the poly $\mathrm{SiGeC}$ in not known.

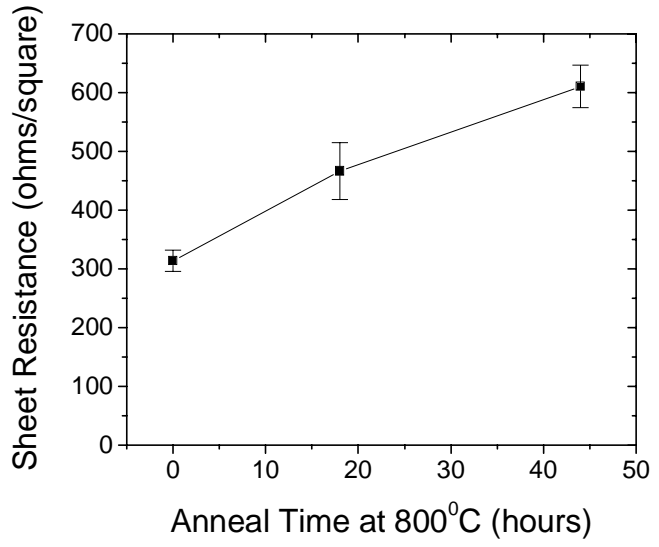

(a)

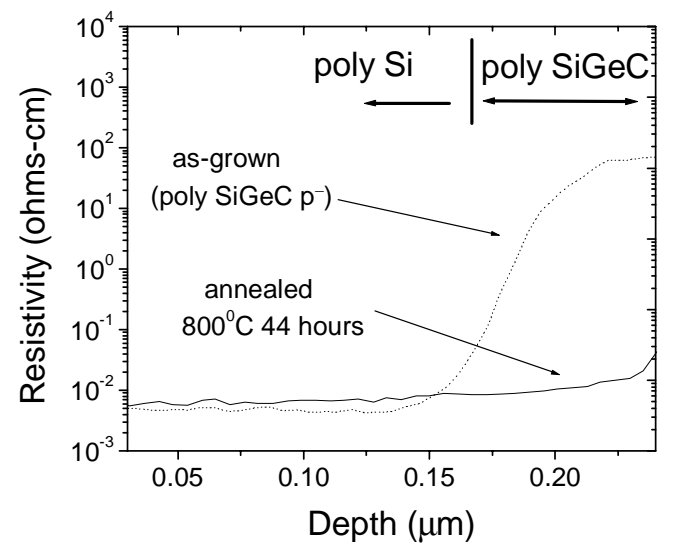

(b)

Figure 4: (a) Sheet resistance and (b) spreading resistance vs. anneal time at $800^{\circ} \mathrm{C}$ for the two layer poly $\mathrm{Si} /$ poly $\mathrm{SiGeC}$ sample. 
This higher resistance in the poly $\mathrm{SiGeC}$ is inconsistent with the single layer results (figure 3), which showed that poly $\mathrm{Si}$ and poly $\mathrm{SiGeC}$ have similar resistivities after being subjected to the same annealing procedure. There are several possibilities for this difference. First, some boron may be associated with carbon-related defects in both samples (and hence be electrically inactive), but this is not detected in the heavily doped single-layer poly $\mathrm{SiGeC}$ sample because only a fraction of the boron is conductive anyway (total boron concentration in the single-layer sample was $\sim 10^{20} \mathrm{~cm}^{-3}$, electrically active boron was only $\sim 5 \times 10^{19} \mathrm{~cm}^{-3}$, see figure 3 ). Second, the strain in the poly Si or poly $\mathrm{SiGeC}$ in the two-layer structure may be different than in the single layer samples, particularly if there was a columnar grain structure and the epitaxy within a grain were pseudomorphic. The large difference in strain could cause a difference in conductivities of the two samples. Third, in the multilayer case, the boron presumably entered the layer via grain boundary diffusion, instead of being grown in-situ, as with the single layer case. Experiments to elucidate the implications of the difference between the single and multilayer samples are in progress.

\section{CONCLUSIONS}

Boron-doped poly $\mathrm{SiGeC}$ is of great interest as a gate material for $\mathrm{p}$-channel MOSFETs. Boron segregates to polycrystalline $\mathrm{SiGeC}$ layers with high levels of carbon. For $\mathrm{Ge}=25 \%$ and $\mathrm{C}=1.5 \%$, the concentration ratio is $\sim 4$ between poly $\mathrm{SiGeC}$ and poly $\mathrm{Si}$ after annealing for 44 hours at $800^{\circ} \mathrm{C}$ in $\mathrm{N}_{2}$. Heavily in-situ doped poly SiGeC does not lose conductivity during long anneals at $800^{\circ} \mathrm{C}$, indicating that boron is not being deactivated by forming $\mathrm{C}$-related defects. These layers have a resisitivity that closely tracks that of similarly doped poly Si layers. However, when boron is diffused into an initially lightly doped poly $\mathrm{SiGeC}$ layer, the resulting conductivity of the poly $\mathrm{SiGeC}$ appears less than when doped in-situ. The cause of this discrepancy is under further investigation.

\section{ACKNOWLEDGEMENTS}

This work was supported by DARPA and ARO.

\section{REFERENCES}

1. C.L.Chang and J.C. Sturm, Applied Physics Letters 74, 2501 (1999).

2. J.R. Pfiester, F.K. Baker, T.C. Mele, H. Tseng, P.J. Tobin, J.D. Hayden, J.W. Miller, C.D. Gunderson, and L.C. Parrillo, IEEE Trans. Electron Devices ED-37, 1842 (1990).

3. E. J. Stewart, M S. Carroll, and J.C. Sturm, ECS $199^{\text {th }}$ meeting (March 2001).

4. M.S. Carroll, L.D. Lanzerotti, and J.C. Sturm, MRS Symp. Proc. 527, 417 (1998).

5. C.W.Liu, A. St. Amour, J.C. Sturm, Y.R.J. Lacroix, M.L.W. Thewalt, C.W. Magee, and D. Eaglesham, Journal of Applied Physics 80, 3043 (1996).

6. S.M. Hu, D.C Ahlgren, P.A. Ronsheim, and J.O. Chu, Physical Review Letters 67, 1450 (1991).

7. S.M. Hu, Physical Review Letters, 63, 2492 (1989).

8. K. Suzuki, N. Miyata, and K. Kawamura, Jpn. J. of Appl. Phys. 34, 1748 (1998). 